\title{
Endogenous Alkaline Transients Boost Postsynaptic NMDA Receptor Responses in Hippocampal CA1 Pyramidal Neurons
}

\author{
Sachin Makani and Mitchell Chesler \\ Departments of Neurosurgery and Physiology and Neuroscience, New York University School of Medicine, New York, New York 10016
}

In hippocampus, activation of the Schaffer collaterals generates an extracellular alkaline transient both in vitro and in vivo. This pH change may provide relief of the $\mathrm{H}^{+}$block of NMDA receptors (NMDARs) and thereby increase excitability. To test this hypothesis, we augmented extracellular buffering in mouse hippocampal slices by adding $2 \mu \mathrm{m}$ bovine type II carbonic anhydrase to the superfusate. With addition of enzyme, the alkaline transient elicited by a 10 pulse, $100 \mathrm{~Hz}$ stimulus train was reduced by $33 \%$. At a holding potential $\left(V_{\mathrm{H}}\right)$ of $-30 \mathrm{mV}$, the enzyme decreased the half-time of decay and charge transfer of EPSCs by 32 and $39 \%$, respectively, but had no effect at a $V_{\mathrm{H}}$ of $-80 \mathrm{mV}$. In current clamp, a 10 pulse, $100 \mathrm{~Hz}$ stimulus train gave rise to an NMDAR-dependent afterdepolarization (ADP). Exogenous enzyme curtailed the ADP half-width and voltage integral by 20 and $25 \%$, respectively. Similar reduction of the ADP was noted with a brief $12 \mathrm{~Hz}$ stimulus train. The effect persisted in the presence of GABAergic antagonists or the $\mathrm{L}^{-t y p e} \mathrm{Ca}^{2+}$ channel blocker methoxyverapamil hydrochloride but was absent in the presence of the carbonic anhydrase inhibitor benzolamide or when the exogenous enzyme was heat inactivated. The effects of the enzyme in voltage and current clamp were noted in $0 \mathrm{Mg}^{2+}$ media but were abolished when (+)-5-methyl-10,11-dihydro-5H-dibenzo[a,d]-cyclohepten-5,10-imine maleate was included in the patch pipette. These results provide strong evidence that endogenous alkaline transients are sufficiently large in the vicinity of the synapse to augment NMDAR responses.

Key words: benzolamide; $\mathrm{pH}$ microelectrode; carbonic anhydrase; stratum radiatum; afterdepolarization; MK-801

\section{Introduction}

Changes in extracellular $\mathrm{pH}$ accompany synchronous neural activity in many brain regions (Chesler, 2003). In the hippocampal CA1 region, stimulation of the Schaffer collaterals elicits an alkaline transient within tens of milliseconds (Tong et al., 2006). This alkalosis represents a net loss of extracellular $\mathrm{H}^{+}$that is buffered by the slow hydration of $\mathrm{CO}_{2}$ according to the following reversible reaction: $\mathrm{CO}_{2}+\mathrm{H}_{2} \mathrm{O} \leftrightarrow \mathrm{HCO}_{3}^{-}+\mathrm{H}^{+}$. The hydration of $\mathrm{CO}_{2}$ is accelerated by endogenous extracellular carbonic anhydrase; however, the activity of this enzyme is low, and the reaction remains out of equilibrium during fast alkaline transients. Therefore, in a rapid time frame the extracellular fluid is poorly buffered, despite the presence of the enzyme. During the rise of an alkaline shift, the effective buffering capacity was estimated to be two orders of magnitude less than that at equilibrium. Thus, the generation of these extracellular alkaline transients requires just a small, momentary addition of strong base on the order of a few micromolar (Tong et al., 2006).

NMDA receptors (NMDARs) are inhibited by extracellular protons in the physiological $\mathrm{pH}$ range (Tang et al., 1990; Trayne-

\footnotetext{
Received May 20, 2007; revised June 5, 2007; accepted June 5, 2007.

This work was supported by National Institutes of Health Grant NS32123 and the Attilio and Olympia Ricciardi Fund.

Correspondence should be addressed to Dr. Mitchell Chesler, Department of Physiology and Neuroscience, New York University School of Medicine, 550 First Avenue, New York, NY 10016. E-mail: mitch.chesler@med.nyu.edu. DOI:10.1523/JNEUROSCI.2304-07.2007

Copyright $\odot 2007$ Society for Neuroscience $\quad$ 0270-6474/07/277438-09\$15.00/0
}

lis and Cull-Candy, 1990; Vyklicky et al., 1990). This has fueled speculation that activity-dependent alkaline transients can provide relief of the tonic $\mathrm{H}^{+}$block and thereby increase excitability. The first studies to address this issue involved inhibition of extracellular carbonic anhydrase, which retards buffering of the alkalosis, causing its enlargement (Chen and Chesler, 1992b). In hippocampal slices, block of the enzyme was associated with a rise in excitability (Taira et al., 1993), prolongation of EPSCs (Gottfried and Chesler, 1994), acceleration of spreading depression (Tong and Chesler, 2000), and increased $\mathrm{Ca}^{2+}$ entry in synaptically activated pyramidal neurons (Fedirko et al., 2007). These effects were dependent on NMDARs and were greater than would be anticipated from the size of the recorded alkaline transients, suggesting that the amplified alkalosis at the postsynaptic membrane was larger than that measured by $\mathrm{pH}$ microelectrodes in the broad extracellular space. These results indicated that extracellular carbonic anhydrase limited excitability by hindering the rise and the summation of alkaline shifts in the vicinity of the synapse.

A compelling unaddressed question is whether these alkaline transients play a modulatory role when normally regulated by this extracellular enzyme. To investigate this issue, one must determine whether excitability is diminished when the alkalosis is suppressed. This might be achieved using an exogenous buffer; however, the large concentrations that are necessary risk numerous nonspecific effects. Here, we have taken an alternate approach. Because of low endogenous extracellular enzyme activity, addition of a very small concentration of exogenous carbonic 
anhydrase (XCA) can markedly augment buffering and diminish alkaline transients (Huang et al., 1995; Tong et al., 2006). We demonstrate that the NMDAR-mediated component of EPSCs in mouse CA1 pyramidal neurons is decreased by XCA. In current clamp, the effect manifested as a marked reduction in the NMDAR-dependent afterdepolarization (ADP). These results provide the first strong evidence that endogenous extracellular alkaline shifts augment excitatory synaptic responses.

\section{Materials and Methods}

Brain slice preparation. Transverse hippocampal slices were prepared from postnatal day 6 (P6) to P14 mice of either sex. All procedures were performed with the approval of the New York University School of Medicine Institutional Animal Care and Use Committee. The brain was blocked in ice-cold artificial CSF (ACSF) and cut into $250 \mu \mathrm{m}$ sagittal slices using a vibratome. A small cut was made between the CA3 and CA1 regions to prevent reverberatory synaptic activation of the CA1 pyramidal neurons. The slices were incubated in standard ACSF at room temperature for at least $1 \mathrm{~h}$ before use. Experiments were then conducted in a submersion-style incubation chamber at $32^{\circ} \mathrm{C}$. The standard ACSF contained the following (in $\mathrm{mm}$ ): $124 \mathrm{NaCl}, 3.0 \mathrm{KCl}, 2.0 \mathrm{CaCl}_{2}, 1.0$ $\mathrm{MgCl}_{2}, 26 \mathrm{NaHCO}_{3}, 1.0 \mathrm{NaH}_{2} \mathrm{PO}_{4}$, and 10 D-glucose, with $\mathrm{pH} 7.4$ (equilibrated with $95 \% \mathrm{O}_{2}$ and $5 \% \mathrm{CO}_{2}$ ). In some experiments, a modified ACSF was used that contained $20 \mathrm{~mm}$ HEPES acid in addition to $26 \mathrm{~mm}$ $\mathrm{HCO}_{3}^{-}$. The HEPES ACSF was formulated using an initial addition of 35 mM $\mathrm{NaHCO}_{3}$ with a compensatory reduction of $\mathrm{NaCl}$ to $109 \mathrm{~mm}$. In $95 \%$ $\mathrm{O}_{2}$ and $5 \% \mathrm{CO}_{2}$, the titration of the HEPES acid produced a final $\mathrm{HCO}_{3}^{-}$ concentration of $26 \mathrm{~mm}$, as judged by an equilibrium pH of 7.4 (MacGregor et al., 2001).

Drugs. Drugs were added either to the external ACSF or to the intracellular pipette solution, as noted, in the following concentrations: DL-2amino-5-phosphonovalerate (APV; $100 \mu \mathrm{M})$, benzolamide $(20 \mu \mathrm{M})$, bovine type II carbonic anhydrase $(2 \mu \mathrm{M})$, methoxyverapamil hydrochloride (D-600; $1 \mathrm{~mm}$ ), (+)-5-methyl-10,11-dihydro-5H-dibenzo [a,d]-cyclohepten-5,10-imine maleate (MK-801; $1 \mathrm{~mm})$, nystatin (300 $\mu \mathrm{g} / \mathrm{ml})$, phaclofen $(100 \mu \mathrm{M})$, picrotoxin $(100 \mu \mathrm{M})$, and lidocaine $N$-ethyl bromide (QX-314; $4 \mu \mathrm{M}$ ). Benzolamide was a gift from Dr. Erik Swenson (University of Washington, Seattle, WA). APV was purchased from Tocris Bioscience (Ellisville, MO). All other agents were obtained from Sigma-Aldrich (St. Louis, MO). To heat inactivate type II carbonic anhydrase, $2 \mu \mathrm{mol}$ of the enzyme were dissolved in $100 \mathrm{ml}$ of a $10 \mathrm{~mm}$ phosphate solution (titrated to $\mathrm{pH} 7.0$ with $\mathrm{NaOH}$ ) and incubated in a constant temperature bath at $65^{\circ} \mathrm{C}$ for $90 \mathrm{~min}$ (Lavecchia and Zugaro, 1991; Almstedt et al., 2004). The inactivated enzyme, $\mathrm{Na}^{+}$, and phosphate in this solution were then diluted 10 -fold in the formulation of $1 \mathrm{~L}$ of ACSF.

Concentric $\mathrm{pH}$-selective microelectrodes. $\mathrm{pH}$-selective microelectrodes with response times of a few milliseconds were fabricated as detailed by Fedirko et al. (2006). In brief, a thin-walled borosilicate glass capillary with outer diameter (OD) of $2.0 \mathrm{~mm}$ and inner diameter (ID) of $1.6 \mathrm{~mm}$ (catalog \#6185; A-M Systems, Carlsborg, WA) was pulled in two steps to a tip size of $2-4 \mu \mathrm{m}$ and then silanized by two sequential injections of pure $N, N$-dimethyltrimethylsilylamine, followed by heating with a hot air gun. A pH-selective mixture (catalog \#95291; Fluka) was then introduced into the tip by suction. The inner micropipette was pulled from thin-walled glass (OD, $1.2 \mathrm{~mm}$; ID, $0.9 \mathrm{~mm}$; catalog \#6160; A-M Systems) to a tip diameter of $\sim 1 \mu \mathrm{m}$. This pipette was filled with phosphatebuffered $3 \mathrm{M} \mathrm{KCl}, \mathrm{pH}$ 7.4, and inserted within the outer, ion-selective barrel and into the ion exchange column. With its tip 4-6 $\mu \mathrm{m}$ from the end of the outer pipette, the inner pipette was secured in place with dental wax. The $\mathrm{pH}$ microelectrodes were calibrated in $50 \mathrm{~mm} \mathrm{~K}{ }^{+} / \mathrm{Na}^{+}$phosphate buffers of $\mathrm{pH} 6.87$ and 7.42. The mean response time constant of similar concentric $\mathrm{pH}$ microelectrodes constructed in this laboratory was reported to be $15 \mathrm{~ms}$ (Fedirko et al., 2006).

Extracellular $\mathrm{pH}$ recordings were performed in the CA1 stratum radiatum. Reference and $\mathrm{pH}$-sensing barrels were connected to highimpedance head stages with input resistance $>10^{13} \Omega$. The concentric $\mathrm{pH}$ microelectrode was mounted on a dual micromanipulator with a separate reference microelectrode filled with $2 \mathrm{M} \mathrm{NaCl}$, with a tip separation of $\sim 5-10 \mu \mathrm{m}$, as described by Fedirko et al. (2006). The dual array was then advanced until the evoked orthodromic field potential was maximal, which was typically at a depth of $100-150 \mu \mathrm{m}$. Capacitance neutralization was used to match the time constant of the reference and $\mathrm{pH}$ electrodes, as judged by the response to a $1 \mathrm{~ms}, 1 \mathrm{mV}$ calibration pulse in the common ground circuit. DC potentials recorded on the reference barrel were continuously subtracted from the $\mathrm{pH}$ recording. The resulting $\mathrm{pH}$ signal was filtered at $2 \mathrm{kHz}$. Absolute baseline extracellular $\mathrm{pH}$ was determined by the potential difference between the ACSF, pH 7.4, and the extracellular fluid of the slice at a tissue depth of $150 \mu \mathrm{m}$.

Whole-cell recording. Pyramidal neurons of the CA1 region were visualized under infrared differential interference contrast microscopy using a Zeiss (Thornwood, NY) Axioskop 2 Plus fixed-stage microscope fitted with a $40 \times$ water-immersion objective $(0.75$ numerical aperture) and an Olympus Optical (Tokyo, Japan) 150 video camera. Patch pipettes were pulled from $1.5 \mathrm{~mm}$ OD, $1.12 \mathrm{~mm}$ ID borosilicate tubing (World Precision Instruments, Sarasota, FL) using a Narishige (Tokyo, Japan) PP-830 two-stage puller. The intracellular filling solution for voltage-clamp experiments contained the following (in mM): $120 \mathrm{Cs}$-gluconate, $20 \mathrm{KCl}, 25$ Na-HEPES, $2 \mathrm{Mg}_{2}$-ATP, and 4 QX-314. Pipettes had resistances of 3-5 $\mathrm{m} \Omega$. In current-clamp experiments, the solution contained the following (in mM): $120 \mathrm{~K}$-gluconate, $20 \mathrm{KCl}, 2.0 \mathrm{MgCl}_{2}, 25 \mathrm{Na}$-HEPES, and 2 $\mathrm{Mg}_{2}$-ATP. After adjusting the $\mathrm{pH}$ to 7.3 with $\mathrm{CsOH}$ or $\mathrm{KOH}$, respectively, the final osmolarity was $280-290 \mathrm{mOsm}$. Some current-clamp experiments were performed in the perforated-patch configuration. There was no difference in current-clamp results, whether obtained in conventional whole-cell (breakthrough) mode or perforated-patch, and therefore data from these two approaches were combined. In whole-cell configuration, the recordings were allowed to stabilize after breakthrough before data acquisition. When drugs were added to the pipette, at least $15 \mathrm{~min}$ was allowed before starting an experiment. In current clamp, cells were accepted if they had an initial resting membrane potential of at least $-50 \mathrm{mV}$. Hyperpolarizing or depolarizing current was injected as required to bring the membrane potential to nominal -66 $\mathrm{mV}$ before the start of the experiment. In voltage clamp, cells were accepted if they had a series resistance of $<20 \mathrm{M} \Omega$ that did not change by $>20 \%$ during the experiment. Traces were sampled at $400 \mu$ s intervals and filtered at $2 \mathrm{kHz}$. Data were acquired using an Axopatch 1D amplifier and Digidata board 1320A controlled by Clampex 8.2 and analyzed using ClampFit (Molecular Devices, Union City, CA). Records in the figures are averages of three to five raw traces.

Stimulation. The Schaffer collateral fibers were activated by constantcurrent pulses of $200 \mu \mathrm{s}$ duration, delivered by a twisted pair of $50 \mu \mathrm{m}$ diameter, Teflon-insulated platinum-iridium wires. In voltage clamp, pulse intensity was adjusted to elicit a consistent EPSC of a few hundred picoamperes. When studying single EPSCs, the Schaffer collaterals were stimulated every $30 \mathrm{~s}$. When studying summated EPSCs, a test train was given at $1 \mathrm{~min}$ intervals. In current clamp, intensity was adjusted to the minimum level that would elicit a consistent ADP in response to a given stimulus train, and these trains were repeated at $45 \mathrm{~s}$ intervals. When using MK-801 in the patch pipette, these periodic stimulation paradigms were performed while the cell was dialyzed, permitting the open channel block of NMDARs to develop (Huettner and Bean, 1988).

Data analysis. Statistics were presented as means with SE. Unless indicated, values of $n$ refer to the number of neurons studied. Dual comparisons between mean values were made with a two-tailed, Student's paired or unpaired $t$ test, as appropriate. The half-width of postsynaptic depolarization was based on the amplitude of the depolarization, measured from prestimulus resting potential to the most negative excursion of the train of action potentials that arose from the top of the depolarizing envelope. The voltage integral or charge transfer was determined by taking the area under the traces between the baseline time point immediately before stimulation and the time point at which the response recovered to baseline.

\section{Results}

Suppression of alkaline transients by XCA

Addition of XCA to ACSF was previously shown to reduce extracellular alkaline transients in rat hippocampal slices, whether 


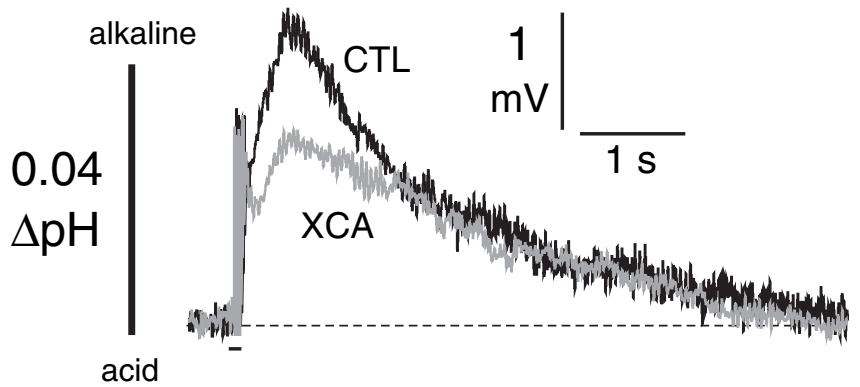

Figure 1. Suppression of stimulus-evoked alkaline transients by XCA. Superimposed alkaline transients recorded in area CA1 stratum radiatum in response to 10 pulse, $100 \mathrm{~Hz}$ stimulation (black bar) of the Schaffer collaterals (recording depth, $\sim 100 \mu \mathrm{m}$ ) are shown. Control trace (CTL; black) and record after superfusion of XCA (gray) are shown.

these $\mathrm{pH}$ changes were induced by synaptic activation or artificially by microinjection of $\mathrm{NaOH}$ (Huang et al., 1995; Tong et al., 2006). This effect could be reproduced in mouse hippocampal slices, as shown in Figure 1. Stimulation of the Schaffer collaterals (10 pulses at $100 \mathrm{~Hz}$ ) elicited an alkaline transient with a peak amplitude of $0.044 \pm 0.004$ unit $\mathrm{pH}$, which was reduced to $0.029 \pm 0.003(n=10$ slices; $p<0.001)$ after addition of $2 \mu \mathrm{M}$ XCA to the ACSF. The earliest components of the alkaline transient were obscured by the stimulus artifacts, but suppression of the response was evident as early as $500 \mathrm{~ms}$ after the onset of stimulation, when the control amplitude of $0.026 \pm 0.004$ fell to $0.021 \pm 0.004(n=10 ; p<0.05)$. The time to peak of the alkaline transient was $1216 \pm 162 \mathrm{~ms}$ and was not significantly altered by $\mathrm{XCA}$. The enzyme caused a small but significant increase in the baseline extracellular $\mathrm{pH}$, from $7.23 \pm 0.04$ to $7.27 \pm 0.03(p<$ $0.01 ; n=4$ slices $)$.

\section{The effect of XCA on evoked EPSCs}

Pyramidal neurons in the CA1 region were studied in the wholecell configuration in standard ACSF containing $100 \mu \mathrm{M}$ picrotoxin. In six cells, single EPSCs were elicited at alternating holding potentials of -30 and $-80 \mathrm{mV}$, before and after addition of exogenous enzyme. At a holding potential of $-80 \mathrm{mV}$, addition of XCA had no significant effect on the peak amplitude, which measured $469 \pm 83 \mathrm{pA}$ in control versus $415 \pm 106 \mathrm{pA}$ with XCA. At this holding potential, the EPSCs had little or no NMDARmediated component, as was evident from their short half-time of decay (Hestrin et al., 1990). The normalized decay half-time was $6.8 \pm 0.4 \mathrm{~ms}$ and was unchanged after addition of XCA, when it measured $7.5 \pm 0.8 \mathrm{~ms}$. The total charge transfer was also unaltered and measured $8.4 \pm 1.9 \mathrm{pC}$ before and $7.9 \pm 2.1 \mathrm{pC}$ after addition of the enzyme. An overlay of traces obtained before and after superfusion of XCA, at a holding potential of $-80 \mathrm{mV}$, is shown in Figure $2 \mathrm{~A}$.

In contrast, at a holding potential of $-30 \mathrm{mV}$, XCA had a significant effect on the peak amplitude, which measured $284 \pm$ $38 \mathrm{pA}$ in control versus $230 \pm 43 \mathrm{pA}$ after addition of the enzyme $(n=6 ; p<0.05)$. At this potential, the EPSCs had a large NMDAR-mediated component, evident from their longer halftime of decay. The normalized decay half-time was $54 \pm 6.5 \mathrm{~ms}$ and was significantly reduced after addition of XCA, when it measured $37 \pm 6.0 \mathrm{~ms}(p<0.05)$. The total charge transfer was also reduced, measuring $30 \pm 7.1 \mathrm{pC}$ before versus $20 \pm 5.3 \mathrm{pC}$ after addition of XCA $(p<0.01)$. Superimposed traces obtained before and after superfusion of XCA, at a holding potential of $-30 \mathrm{mV}$, are shown in Figure $2 B$.
In view of the voltage-dependent block by $\mathrm{Mg}^{2+}$ on NMDARs (Nowak et al., 1984), the contrasting effect of XCA at -30 versus $-80 \mathrm{mV}$ suggested a specific action on these channels. To test this pharmacologically, we avoided the use of bath-applied NMDAR antagonists such as APV. This was necessary because the consequent decrease in overall tissue excitability causes a marked reduction in stimulus-evoked alkaline responses (Fedirko et al., 2007), which could obscure the buffer-mediated effects of XCA. We therefore used the noncompetitive NMDAR antagonist MK801 intracellularly, thereby blocking NMDAR-mediated currents from the recorded cell only (Berretta and Jones, 1996; Mameli et al., 2005; Samson and Pare, 2005). To render this method most effective, we used $0 \mathrm{Mg}^{2+}$ ACSF (Huettner and Bean, 1988). For five cells studied at a holding potential of $-30 \mathrm{mV}$, the amplitude of EPSCs recorded with $1 \mathrm{mM}$ intracellular MK-801 was unchanged by the enzyme, with a peak of $268 \pm 51$ pA before versus $240 \pm 50 \mathrm{pA}$ after addition of XCA. The EPSCs had a normalized decay half-time of $15.4 \pm 5.2 \mathrm{~ms}$, consistent with a large block of the NMDAR component of the current. The normalized halftime was unaltered in XCA, in which it measured $16.5 \pm 6.5 \mathrm{~ms}$. The total charge transfer was also unchanged by XCA, measuring $9.2 \pm 4.3 \mathrm{pC}$ before versus $7.4 \pm 3.3 \mathrm{pC}$ after addition of the enzyme. An overlay of traces obtained with MK- 801 in the pipette before and after superfusion of XCA is shown in Figure 2C.

Studies of activity-dependent, extracellular alkaline shifts have commonly used trains of stimuli to generate temporally summated $\mathrm{pH}$ changes (Chen and Chesler, 1992a; Taira et al., 1995; Tong et al., 2006). It was therefore of interest to study the effect of XCA on the corresponding summated synaptic currents. During a repetitive stimulus train, a number of forms of plasticity can affect the amplitude of the summated current. However, at a holding potential of $-30 \mathrm{mV}$, the decay of that current would be governed largely by NMDARs and therefore should be sensitive to XCA, as above.

After 10 stimuli to the Schaffer collaterals at $100 \mathrm{~Hz}$, the normalized half-time of decay of the current was $140 \pm 19 \mathrm{~ms}$ and was significantly reduced to $110 \pm 18 \mathrm{~ms}$ after addition of XCA $(n=7 ; p<0.01)$. Superimposed traces from such an experiment are shown in Figure $3 A$. To test the NMDAR dependence of this effect, we again used intracellular MK-801 in $0 \mathrm{Mg}^{2+}$ ACSF. Because much larger currents could be elicited in this saline, we limited the stimulus train to three pulses at $100 \mathrm{~Hz}$ to attain response magnitudes comparable with those in standard ACSF. In control experiments without MK-801 in the pipette, the normalized decay half-time after the train was significantly reduced by XCA and measured $106 \pm 18 \mathrm{~ms}$ before versus $90 \pm 15 \mathrm{~ms}$ after addition of the enzyme $(n=6 ; p<0.05)$. One example with overlaid traces is shown in Figure $3 B$. In contrast, with MK-801 included in the pipette, the normalized decay half-time was unchanged by XCA, measuring $10.2 \pm 2.7$ ms before versus $10.0 \pm$ $2.9 \mathrm{~ms}$ after addition of XCA $(n=5)$. Records obtained before and after XCA are superimposed in Figure $3 C$.

\section{The effect of XCA on responses in current clamp}

In rat hippocampus, brief, high-frequency or high-intensity stimulation of the Schaffer collaterals elicits a depolarizing envelope that triggers a burst of action potentials, followed by a longlasting NMDAR-dependent ADP (Ariav et al., 2003; Enoki et al., 2004; Wu et al., 2004; Fan et al., 2005; Fedirko et al., 2007). These ADPs are often, but not always, followed by a slow afterhyperpolarization (AHP) (Wu et al., 2004). In the mouse preparation, it was possible to elicit consistent ADPs by short stimulus trains using frequencies from 12 to $100 \mathrm{~Hz}$ (Fig. $4 A, B$ ). Because these 
A
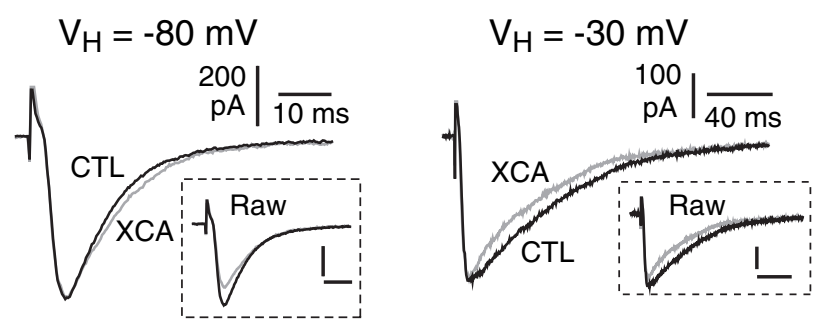

Figure 2. Effect of XCA on single evoked EPSCs. $A$, Comparison of normalized control (CTL) versus XCA traces at a $V_{H}$ of $-80 \mathrm{mV}$. Raw traces before normalization are shown in the inset, with calibration bars indicating the same time and current scale as in normalized records. $\boldsymbol{B}$, Comparison of EPSCs at a $V_{H}$ of $-30 \mathrm{mV}$. Note the shortening of the decay after addition of enzyme (gray). C, Comparison of superimposed EPSCS at a $V_{H}$ of $-30 \mathrm{mV}$ with $1 \mathrm{~mm}$ intracellular MK- $801,0 \mathrm{Mg}^{2+}$ ACSF. Note the absence of effect after adding enzyme (gray overlay).

responses were also found to be highly dependent on NMDARs (see below), current-clamp experiments were focused around the ADP.

In the presence of XCA, the ADPs were consistently curtailed. In four cells activated by a five pulse, $12 \mathrm{~Hz}$ train, the half-width measured $1196 \pm 180$ ms before versus $936 \pm 163$ ms after addition of XCA $(p<0.05)$. The voltage integral was also reduced by $\mathrm{XCA}$, measuring $5.1 \pm 1.1 \times 10^{4} \mathrm{mV} \cdot \mathrm{ms}$ before versus $3.9 \pm$ $1.2 \times 10^{4} \mathrm{mV} \cdot \mathrm{ms}$ after addition of the enzyme $(p<0.05)$. An example of superimposed responses to a $12 \mathrm{~Hz}$ train is shown in Figure $4 A$. ADPs could be elicited most consistently using a 10 pulse, $100 \mathrm{~Hz}$ stimulus train; therefore this set of stimulus parameters was chosen as the standard testing protocol. In 14 cells, this train evoked a response with a half-width of $1130 \pm 56 \mathrm{~ms}$ before versus $896 \pm 50 \mathrm{~ms}$ after addition of XCA $(p<0.001)$ and a voltage integral that was reduced from $3.6 \pm 0.3 \times 10^{4} \mathrm{mV} \cdot \mathrm{ms}$ before versus $2.7 \pm 0.2 \times 10^{4} \mathrm{mV} \cdot \mathrm{ms}$ after addition of the enzyme $(p<0.001)$. An example of this effect is shown in Figure $4 B$. This decrement occurred late in the postsynaptic response; there was no significant change in the amplitude of the depolarization at $500 \mathrm{~ms}$, a time at which XCA had already decreased the alkaline transient (see Discussion). The effect of XCA on the ADP could be reversed after return to normal ACSF (data not shown); however, stable recordings could not be routinely maintained during the additional 20-30 min required for washout. The resting membrane potential was not altered by the enzyme and averaged $-66 \pm 0.4$ versus $-65 \pm 0.6 \mathrm{mV}$, before and after addition of XCA, respectively $(n=18)$.

To determine how the action of XCA on the ADP would compare against a complete block of NMDARs, we measured the response to a 10 pulse, $100 \mathrm{~Hz}$ train before and after superfusion of $100 \mu \mathrm{M}$ APV. In four cells, APV reduced the half-width of the ADP by $31 \pm 1.5 \%(p<0.001)$ and the decreased the voltage integral by $45 \pm 7.1 \%(p<0.05)$. By comparison, in the 14 cells studied above, XCA suppressed the half-width and voltage integral by $20 \pm 2.7$ and $25 \pm 3.9 \%$, respectively. Thus, in curtailing these parameters of the ADP, addition of XCA was approximately one-half as effective as $100 \mu \mathrm{M}$ APV.

The washin time for the effect of XCA was $\sim 10 \mathrm{~min}$. To test whether presynaptic or postsynaptic run down over this time span might account for the shortened ADPs, a comparison was made of responses elicited by 10 pulse, $100 \mathrm{~Hz}$ trains separated by a $10 \mathrm{~min}$ interval. In five cells, there was no significant difference in the half-width, which measured $1020 \pm 154$ ms before versus $953 \pm 164 \mathrm{~ms}$ after the $10 \mathrm{~min}$ interval. The voltage integral was also unchanged and measured $3.1 \pm 0.6 \times$ $10^{4} \mathrm{mV} \cdot \mathrm{ms}$ before versus $2.8 \pm 0.5 \times 10^{4}$ $\mathrm{mV} \cdot \mathrm{ms}$ after the $10 \mathrm{~min}$ span. Traces obtained before and after this interval are shown in Figure $4 D$.

We tested the NMDAR dependence of the XCA effect using $0 \mathrm{Mg}^{2+}$ ACSF, with or without MK-801 in the patch pipette. In the absence of MK-801, XCA significantly shortened the half-width from $1155 \pm 130$ to $926 \pm 91 \mathrm{~ms}(n=8 ; p<0.05)$ and decreased the voltage integral from $4.2 \pm$ $0.7 \times 10^{4}$ to $3.3 \pm 0.6 \times 10^{4} \mathrm{mV} \cdot \mathrm{ms}(p<$ $0.01)$. One such example is shown in Figure $5 A$. With MK-801, XCA had no effect on the half-width, which was $496 \pm 64 \mathrm{~ms}$ before versus $485 \pm 77 \mathrm{~ms}$ after addition of the enzyme $(n=5)$. The voltage integral was also unchanged, measuring $1.5 \pm 0.3 \times 10^{4} \mathrm{mV} \cdot \mathrm{ms}$ before versus $1.4 \pm 0.3 \mathrm{mV} \cdot \mathrm{ms}$ after addition of XCA (Fig. $5 B$ ). With MK-801 included in the pipette, the baseline ADP was significantly shortened compared with control cells ( $p<0.01$; unpaired $t$ test), consistent with the block of NMDARs.

To test whether the effect of XCA on the ADP was attributable to the specific catalytic action of the enzyme, experiments were conducted on seven cells in the presence of the poorly permeant carbonic anhydrase inhibitor benzolamide $(20 \mu \mathrm{M})$. The halfwidth of the response was unaffected when the enzyme was added with its inhibitor already present and measured $987 \pm 124 \mathrm{~ms}$ before versus $970 \pm 131 \mathrm{~ms}$ after application of XCA. The voltage integral was also unaltered and was $3.8 \pm 0.4 \times 10^{4} \mathrm{mV} \cdot \mathrm{ms}$ before versus $3.6 \pm 0.4 \times 10^{4} \mathrm{mV} \cdot \mathrm{ms}$ after addition of the enzyme. An example of records obtained in the presence of benzolamide is shown in Figure $6 \mathrm{~A}$.

Heat inactivation of the enzyme also abolished its effect on the ADP. In four cells, the half-width of the response was $1176 \pm 121$ ms before versus $1201 \pm 134 \mathrm{~ms}$ after addition of heat-treated $\mathrm{XCA}$. The voltage integral was similarly unaffected and measured $4.3 \pm 0.6 \times 10^{4} \mathrm{mV} \cdot \mathrm{ms}$ before versus $4.9 \pm 0.5 \times 10^{4} \mathrm{mV} \cdot \mathrm{ms}$ after the denatured enzyme was added. Superimposed traces from one such experiment are shown in Figure $6 B$.

GABAergic responses could be influenced by the catalytic action of carbonic anhydrase, because $\mathrm{GABA}_{\mathrm{A}}$ currents can be sensitive to extracellular $\mathrm{pH}$ and contain a significant component carried by bicarbonate ions (Kaila, 1994). However, for five cells studied in the combined presence of the $\mathrm{GABA}_{\mathrm{A}}$ antagonist picrotoxin $(100 \mu \mathrm{M})$, as well as the $\mathrm{GABA}_{\mathrm{B}}$ antagonist phaclofen $(100 \mu \mathrm{M})$, superfusion of XCA still significantly reduced the halfwidth and voltage integral. Under these conditions, the halfwidth fell from $834 \pm 122$ to $654 \pm 107 \mathrm{~ms}(p<0.05)$, and the voltage integral fell from $4.7 \pm 0.7$ to $3.7 \pm 0.5 \times 10^{4} \mathrm{mV} \cdot \mathrm{ms}$ $(p<0.05)$, before and after addition of XCA, respectively. This effect of the enzyme was not different from the reduction in half-width and voltage integral noted in the absence of the GABA receptor antagonists (unpaired, two-tailed Student's $t$ test). Traces obtained in the presence of these GABA antagonists are shown in Figure $7 A$.

L-type $\mathrm{Ca}^{2+}$ channels are sensitive to extracellular $\mathrm{pH}$ near the physiological range (Iijima et al., 1986; Barnes and Bui, 1991; Chen et al., 1996) and might therefore be influenced by the enhanced buffering caused by XCA. With the L-type channel antagonist D-600 in the patch pipette (Schiller, 2004), there was no effect on the baseline ADP, and the addition of XCA still caused a 


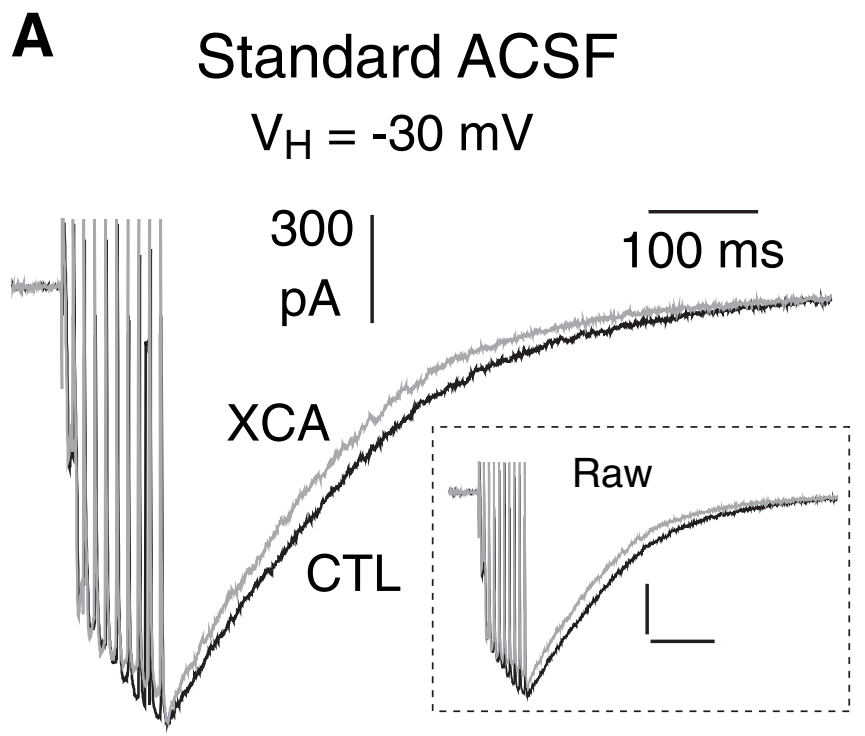

\section{B \\ $0 \mathrm{Mg}^{2}+$ Control

$$
\mathrm{V}_{\mathrm{H}}=-80 \mathrm{mV}
$$

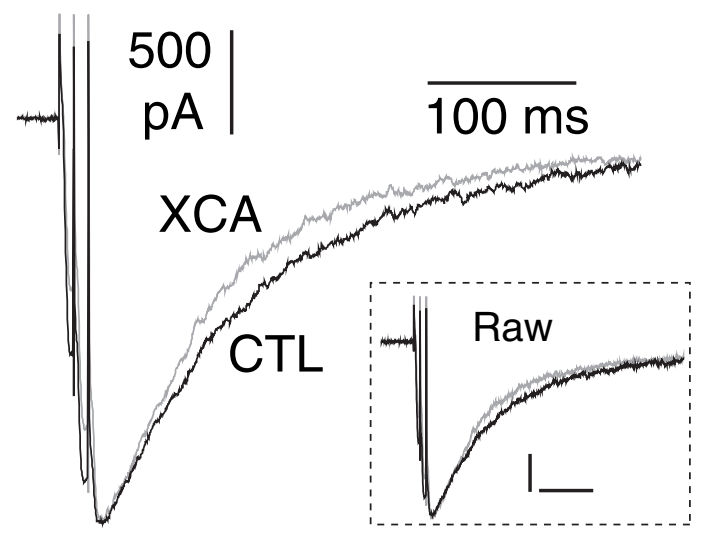

C

$$
\begin{gathered}
0 \mathrm{Mg}^{2}+/ \mathrm{MK}-801 \\
\mathrm{~V}_{\mathrm{H}}=-80 \mathrm{mV}
\end{gathered}
$$

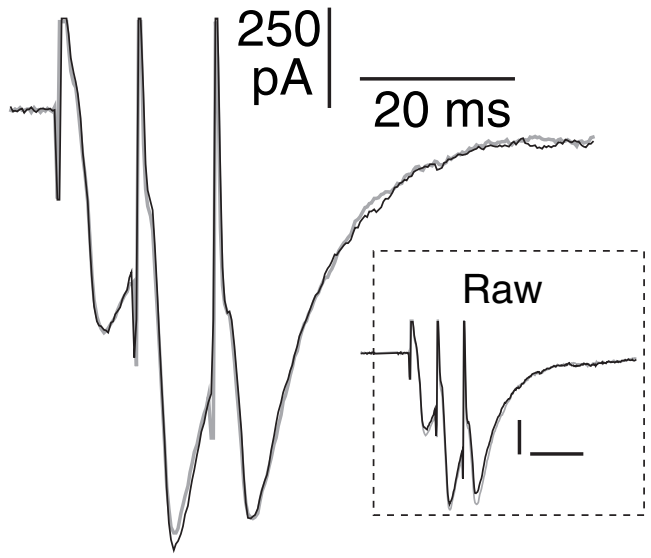

significant curtailment of the ADP in seven cells. The half-width measured $971 \pm 44 \mathrm{~ms}$ before versus $854 \pm 38 \mathrm{~ms}$ after addition of XCA $(p<0.001)$. The voltage integral was $3.7 \pm 0.3 \times 10^{4} \mathrm{mV}$ $\cdot \mathrm{ms}$ before versus $3.3 \pm 0.3 \times 10^{4} \mathrm{mV} \cdot \mathrm{ms}$ after the enzyme was added $(p<0.05)$. Although curtailment of the ADP persisted with D-600, the effect was significantly less than that noted in its absence (two-tailed unpaired Student's $t$ test; $p<0.05$ for both half-width and voltage integral). Superimposed traces obtained with D-600 in the pipette are shown in Figure $7 B$.

Curtailment of the ADP could occur if there had been an enhancement of the AHP by the enzyme. An AHP $(>1 \mathrm{mV})$ was noted after the ADP in 11 of 14 cells, with a mean hyperpolarization of $-2.1 \pm 0.2 \mathrm{mV}$. There was no significant effect of XCA on the amplitude of this response. In the presence of external APV or internal MK-801, where the ADP was greatly diminished, an AHP was noted in six of 10 cells, with a mean amplitude of $-3.0 \pm 0.7 \mathrm{mV}$. Addition of XCA again had no effect on the size of this hyperpolarization.

In principle, increasing the buffering capacity with an exogenous buffer such as HEPES would also be expected to reduce the ADP. Adding $20 \mathrm{~mm}$ HEPES did indeed produce a shortening of the ADP, with a decrease in half-width and voltage integral of $12 \pm 2.3 \%(p<0.01)$ and $12 \pm 4.4 \%(p<0.05)$, respectively $(n=8)$. However, this treatment also caused a very marked increase in the AHP of $68 \pm 28 \%(p<0.05)$, which made the reduction of the ADP difficult to interpret (data not shown).

\section{Discussion}

A rapid rise in extracellular $\mathrm{pH}$ at the onset of synchronous neural activity is a prominent feature in many brain regions (Chesler, 2003). The mechanism underlying these alkaline shifts is not known, although $\mathrm{Ca}^{2+}-\mathrm{H}^{+}$exchange via a plasmalemmal $\mathrm{Ca}^{2+}$ ATPase has been suggested as the basis for a surface alkalosis in snail neurons (Schwiening et al., 1993). In the CA1 region of the hippocampus, these alkaline transients arise in tens of milliseconds and can persist for seconds, their amplitude and time course being largely dependent on the activity of extracellular carbonic anhydrase (Tong et al., 2006). In rat hippocampal slices, a decrease in the effective buffering capacity caused by the inhibition of this enzyme amplified alkaline transients, prolonged the NMDAR component of EPSCs (Gottfried and Chesler, 1994), and augmented NMDAR-dependent $\mathrm{Ca}^{2+}$ transients in CA1 pyramidal neurons (Fedirko et al., 2007). These data indicated that the alkaline shift, when not regulated by endogenous extracellular carbonic anhydrase, attains a magnitude in the vicinity of the postsynaptic membrane that is sufficient to increase NMDAR currents.

The central issue of the present study was whether activityevoked alkaline transients are sufficient to boost NMDARmediated responses, despite limitation of the $\mathrm{pH}$ change by endogenous extracellular carbonic anhydrase. The approach to this question was to test for NMDAR-dependent changes in the

\section{$\leftarrow$}

Figure 3. Effect of XCA on summated EPSCS. A, Summated currents in response to 10 pulse, $100 \mathrm{~Hz}$ stimulation of the $S$ chaffer collaterals $\left(V_{\mathrm{H}}=-30 \mathrm{mV}\right)$. Records normalized to the peak control (CTL) current are shown. Note the shortening of decay with XCA (gray). B, Summated currents in $0 \mathrm{Mg}^{2+} \mathrm{ACSF}$ in response to a three pulse, $100 \mathrm{~Hz}$ stimulus train $\left(V_{H}=-80 \mathrm{mV}\right)$. Note the shortening of decay with XCA (gray). C, Summated currents in $0 \mathrm{Mg}^{2+}$ ACSF in response to a three pulse, $100 \mathrm{~Hz}$ stimulus train $\left(V_{H}=-80 \mathrm{mV}\right)$. The pipette contained $1 \mathrm{~mm}$ MK-801. Note the absence of effect after addition of enzyme. Raw traces before normalization are shown in the insets, with calibration bars indicating the same time and current scale as in normalized records. 
A
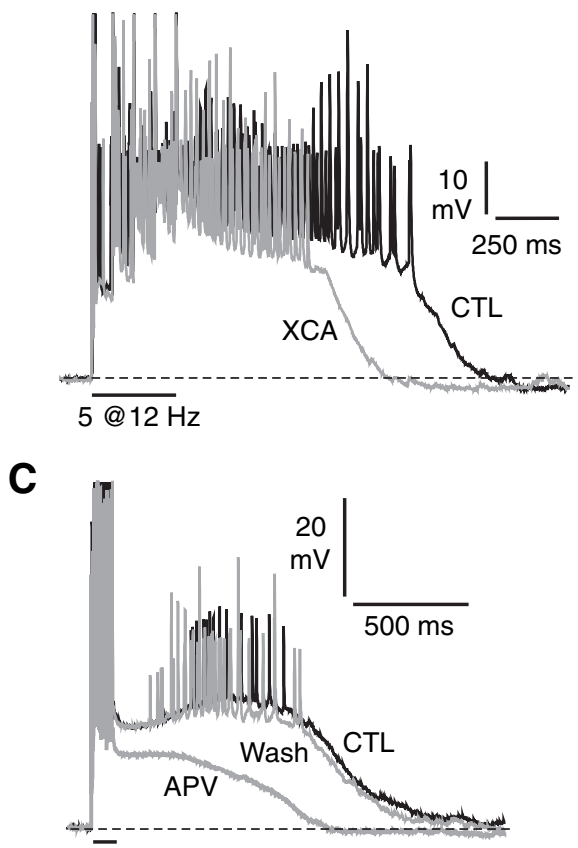

$10 @ 100 \mathrm{~Hz}$
B

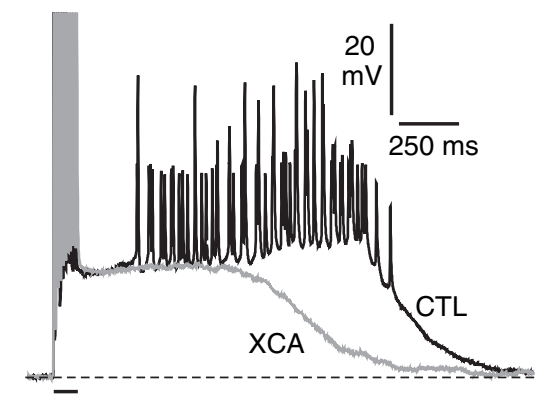

$10 @ 100 \mathrm{~Hz}$

D

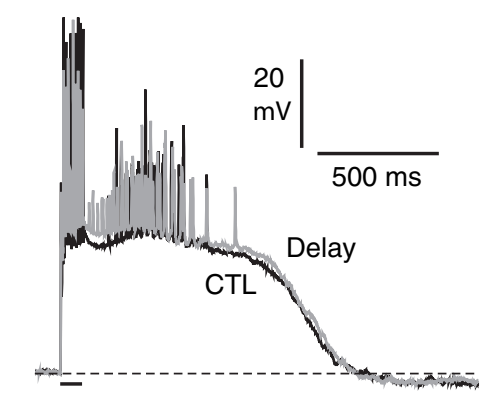

$10 @ 100 \mathrm{~Hz}$

Figure 4. XCA curtailed the ADP. A, Current-clamp response to a five pulse, $12 \mathrm{~Hz}$ stimulus train. Note the marked shortening of the ADP after addition of XCA (gray). $\boldsymbol{B}$, Current-clamp response to a 10 pulse, $100 \mathrm{~Hz}$ stimulus train. ADP was similarly shortened by XCA.C, APV reversibly curtailed the ADP after a 10 pulse, $100 \mathrm{~Hz}$ train. D, Suppression of the ADP was not attributable to run down. Responses to 10 pulse, $100 \mathrm{~Hz}$ stimulus shown for control train (CTL; black) and identical test train (gray) given after a 10 min interval are shown. Records shown here and in subsequent figures are averages of three to five raw traces. As a result, the apparent spike amplitudes are reduced, and the apparent spike frequency is increased, in the averaged traces.

postsynaptic electrical response after an increase in effective extracellular buffering capacity, provided by the addition of XCA. It was shown that the NMDAR component of single and summated EPSCs was moderately but specifically suppressed by addition of the enzyme. In current clamp, the effect manifested as a marked shortening of the ADP that amounted to approximately one-half of the suppression seen when NMDA receptors were completely blocked by APV. In some instances, spike generation in the ADP was entirely arrested after addition of XCA (Fig. $4 \mathrm{~B}$ ).

This curtailment was not attributable to a change in presynaptic function, because XCA had no effect when EPSCs were elicited at a holding potential of $-80 \mathrm{mV}$ in standard ACSF or when responses were evoked with NMDARs blocked by intracellular MK-801. In addition, the shortening of the ADP did not require either GABAergic transmission or L-type $\mathrm{Ca}^{2+}$ channels. Nonspecific effects of the protein could also be ruled out, because the suppression of the ADP was completely absent when the enzyme was heat inactivated or when its active site was blocked by benzolamide. An increase in the AHP could contribute to a diminished ADP; however, the AHP in these neurons was small and was not significantly altered by XCA. Moreover, it is notable that the medium and slow components of the AHP in CA1 neurons are increased by extracellular alkalosis (Kelly and Church, 2004). Because the enzyme reduced the alkaline transient, one might expect these components of the AHP to have been diminished. Such an effect would have tended to prolong, rather than suppress, the ADP (Wu et al., 2004; Fernandez de Sevilla et al., 2007).

The effect of XCA warrants consideration of the nature of the ADP. A number of different mechanisms have been linked to the generation of slow, depolarizing potentials in CA1 pyramidal neurons. In the presence of $\mathrm{K}^{+}$channel blockers, plateau potentials mediated by a $\mathrm{Ca}^{2+}$-dependent, nonspecific cation conductance have been reported, with a dependence on muscarinic (Fraser and MacVicar, 1996; Kuzmiski and MacVicar, 2001) or metabotropic glutamate (Congar et al., 1997) receptors. However, in rat CA1 neurons, an ADP after repetitive stimulation of the Schaffer collaterals that is highly dependent on NMDARs has been noted in vivo (Fan et al., 2005), and when studied in vitro, this NMDAR-mediated response persisted with chelation of intracellular $\mathrm{Ca}^{2+}$ or with application of muscarinic antagonists (Wu et al., 2004). In cortical pyramidal neurons, active NMDAR responses in the basilar dendrites have been described (Schiller et al., 2000), and there is evidence that similar regenerative events contribute to ADPs of CA1 pyramidal neurons (Enoki et al., 2004). A nonlinear response of dendritic NMDARs that exhibits threshold-dependent, bistable behavior (Schiller and Schiller, 2001) may be very susceptible to changes in excitatory drive resulting from relief of the proton block.

Thus, the most plausible interpretation of our findings is that XCA increased the effective extracellular buffering capacity and thereby reduced the activity-dependent alkaline transient. Consequently, relief of the NMDAR proton block rendered by the alkalosis was diminished, and the corresponding NMDAR-dependent responses were more suppressed. Alternatively, one might ponder whether a decrease in excitability was the primary event and the cause of the reduced alkalosis, rather than its consequence. There are several problems with this argument. First, the means by which excitability would be diminished is unexplained. It is not apparent how XCA could reduce NMDAR currents via its active site by means other than catalysis of the reversible hydration of $\mathrm{CO}_{2}$ (i.e., buffering). In addition, it is already well established that the addition of XCA increases extracellular buffering, because it could markedly diminish "artificial" alkaline transients induced by iontophoresis of $\mathrm{NaOH}$ (Huang et al., 1995). Moreover, the reduction of alkaline transients by the enzyme occurred early in their time course. In optical recordings in rat hippocampal slices, where stimulus artifacts did not obscure the onset, a diminished alkaline response was evident within $100 \mathrm{~ms}$ of the stimulus (Tong et al., 2006). In the present study, a large fraction of the reduction of the alkaline transient had occurred by $500 \mathrm{~ms}$, at which time there was still no effect on the amplitude of the ADP. During the subsequent $500 \mathrm{~ms}$, however, the alkaline transient remained suppressed, and the late NMDAR-dependent response was curtailed.

L-type $\mathrm{Ca}^{2+}$ channels might have contributed to this behavior as well, given the significant reduction in the effect of XCA noted in the presence of D-600. These $\mathrm{Ca}^{2+}$ channels could be involved because of their own sensitivity to external pH (Iijima et al., 1986; Barnes and Bui, 1991; Chen et al., 1996) or because of depolarization-mediated, mutually reinforcing interactions with NMDARs.

Compared with other methods of increasing extracellular 
A

\section{$0 \mathrm{Mg}^{2+}$ Control}

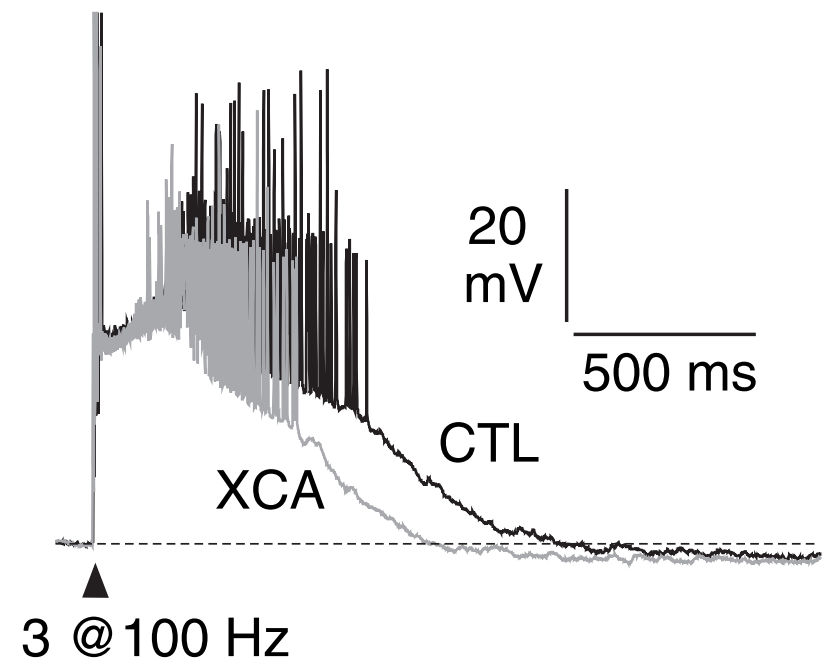

B

\section{$0 \mathrm{Mg}^{2}+\mathrm{MK}-801$}

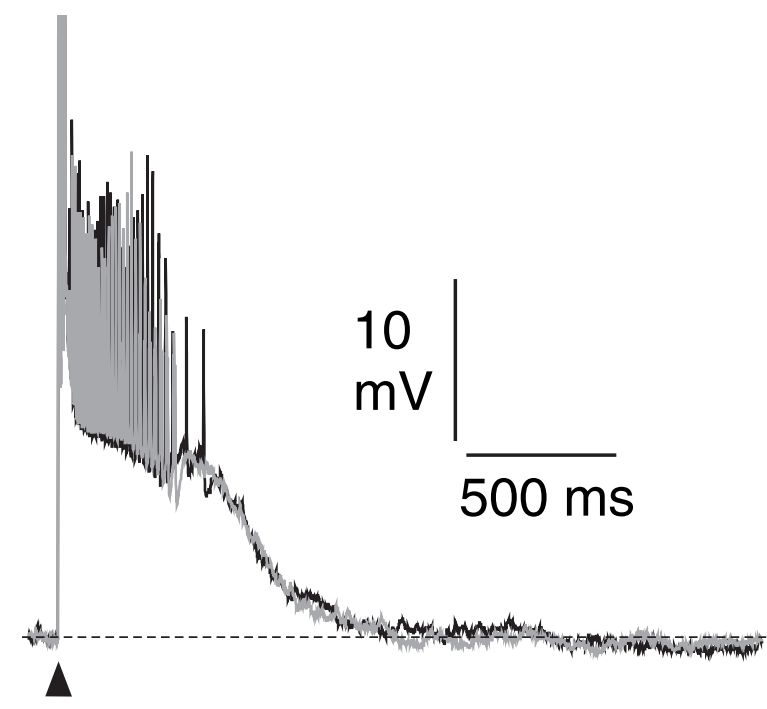

\section{$3 @ 100 \mathrm{~Hz}$}

Figure 5. Suppression of the ADP by XCA is NMDAR dependent. $A$, Responses to a three pulse, $100 \mathrm{~Hz}$ stimulus train (onset at arrowhead) in $0 \mathrm{Mg}^{2+}$ ACSF. Note the marked curtailment of the ADP by XCA (gray). $B$, Responses to three pulse, $100 \mathrm{~Hz}$ stimulus train in $0 \mathrm{Mg}^{2+}$ ACSF with $1 \mathrm{~mm}$ MK-801 in the pipette. Note the absence of effect after addition of enzyme. CTL, Control.

buffering capacity, the use of XCA had distinct advantages. The concentration of enzyme required was extremely low. The augmentation of extracellular buffering noted in this study can be achieved using as little as $300 \mathrm{~nm}$ enzyme (Huang et al., 1995;
A

\section{XCA in Benzolamide}

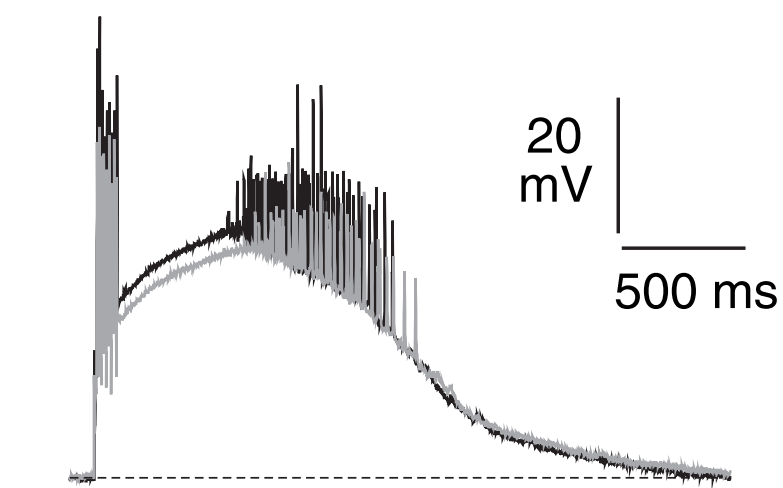

$10 @ 100 \mathrm{~Hz}$

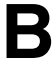

\section{Heat-Inactivated XCA}

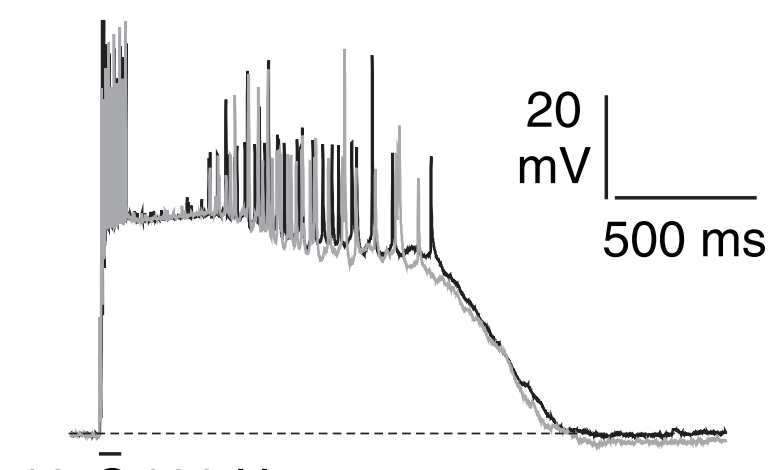

Figure 6. Suppression of the ADP by XCA requires functional enzyme. $A$, Responses to a 10 pulse, $100 \mathrm{~Hz}$ train in the presence of the poorly permeant carbonic anhydrase inhibitor benzolamide $(20 \mu \mathrm{M})$. Note the absence of effect after adding enzyme. $\boldsymbol{B}$, Responses to a 10 pulse, 100 $\mathrm{Hz}$ train. Addition of heat-inactivated enzyme had no effect on the ADP.

Tong et al., 2006). Here, we used a concentration of $2 \mu \mathrm{M}$ so as to enable a rapid onset of effect while recording in the whole-cell configuration. This, however, precluded routine testing of reversibility, because of the long washout time. One unexpected consequence of adding exogenous enzyme was a small but significant increase in baseline extracellular $\mathrm{pH}$. The basis of this effect is unclear; however, it should be noted that a small alkalosis would have tended to increase rather than suppress NMDAR currents (Tang et al., 1990; Traynelis and Cull-Candy, 1990; Vyklicky et al., 1990).

Improved buffering can also be achieved via the addition of HEPES; however, this requires millimolar concentrations (DeVries, 2001; Palmer et al., 2003), making known nonspecific effects of HEPES more of a concern (Yamamoto and Suzuki, 
A

\section{XCA in PTX-Phaclofen}

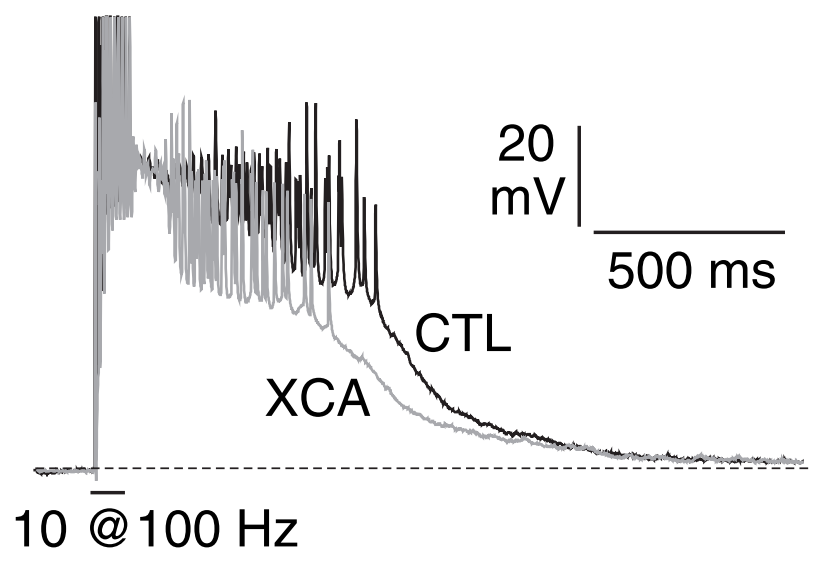

B

\section{D-600}

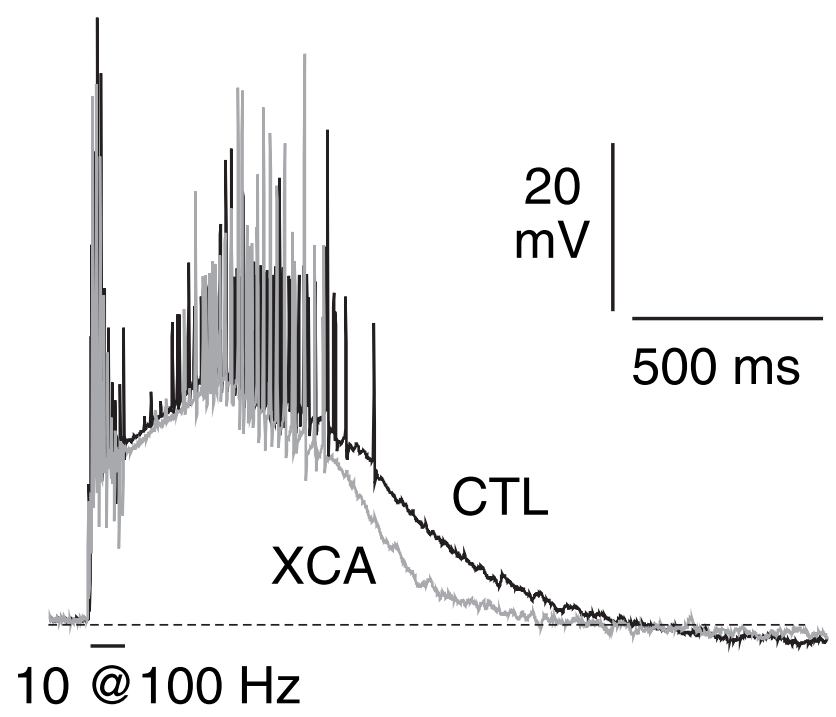

Figure 7. Suppression of ADP by XCA does not require GABAergic transmission or L-type $\mathrm{Ca}^{2+}$ channels. $A$, Responses to a 10 pulse, $100 \mathrm{~Hz}$ train in the presence of picrotoxin (PTX) and phaclofen (both $100 \mu \mathrm{m}$ ). Note the curtailment of the ADP after addition of enzyme (gray). $\boldsymbol{B}$, Responses to a 10 pulse, $100 \mathrm{~Hz}$ train with $1 \mathrm{~mm}$ D-600 in the patch pipette. Note the curtailment of the ADP after addition of enzyme. CTL, Control.

1987; Hanrahan and Tabcharani, 1990; MacGregor et al., 2001). We attempted to increase buffering using ACSF with $20 \mathrm{~mm}$ HEPES (MacGregor et al., 2001). Although this solution caused the expected shortening of the ADP, there was also an enhancement of the AHP, making interpretation problematic.

A sustained rise in $\mathrm{pH}$ equal to the mean peak amplitude of the observed alkaline transients $(0.044$ unit $\mathrm{pH})$ would cause an increase in NMDAR currents of only 2\% (Tang et al., 1990; Traynelis and Cull-Candy, 1990; Vyklicky et al., 1990). Thus, it would appear that the alkaline shifts recorded by concentric $\mathrm{pH}$ microelectrodes were too small to account for the observed effects on NMDARs. For example, the current at $40 \mathrm{~ms}$ could be reduced $20-30 \%$ by XCA (Fig. 2 B). However, these recordings represent the $\mathrm{pH}$ change within the broad interstitial compartment and therefore may be just a dim representation of the $\mathrm{pH}$ shift at the level of the postsynaptic membrane. The fact that NMDAR responses are increased when endogenous extracellular carbonic anhydrase is blocked (Gottfried and Chesler, 1994; Fedirko et al., 2007) and are suppressed when the extracellular enzyme activity is increased provides a symmetric, compelling argument for a larger alkalosis near the synapse. Moreover, one should note that addition of XCA eliminated just a fraction of the alkalosis. This implies that the full augmentation of NMDAR currents caused by these alkaline transients could be considerably greater than that suggested by the present experiments.

In summary, this investigation has provided the first evidence that endogenous alkaline transients facilitate NMDAR-mediated responses. This modulation determines the duration of ADPs that occur in response to afferent stimulation of sufficient frequency or strength (Wu et al., 2004; Fan et al., 2005). Augmentation of this sort may be most significant to epileptic states, in which large alkaline transients have been noted (Somjen, 1984; de Curtis et al., 1998; Xiong and Stringer, 2000) but could also be relevant in physiological instances of highly synchronous network activity, as occurs, for example, during the hippocampal theta rhythm.

\section{References}

Almstedt K, Lundqvist M, Carlsson J, Karlsson M, Persson B, Jonsson BH, Carlsson U, Hammarstrom P (2004) Unfolding a folding disease: folding, misfolding and aggregation of the marble brain syndrome-associated mutant H107Y of human carbonic anhydrase II. J Mol Biol 342:619-633.

Ariav G, Polsky A, Schiller J (2003) Submillisecond precision of the inputoutput transformation function mediated by fast sodium dendritic spikes in basal dendrites of CA1 pyramidal neurons. J Neurosci 23:7750-7758.

Barnes S, Bui Q (1991) Modulation of calcium-activated chloride current via $\mathrm{pH}$-induced changes of calcium channel properties in cone photoreceptors. J Neurosci 11:4015-4023.

Berretta N, Jones RS (1996) Tonic facilitation of glutamate release by presynaptic $N$-methyl-D-aspartate autoreceptors in the entorhinal cortex. Neuroscience 75:339-344.

Chen JC, Chesler M (1992a) Modulation of extracellular $\mathrm{pH}$ by glutamate and GABA in rat hippocampal slices. J Neurophysiol 67:29-36.

Chen JC, Chesler M (1992b) pH transients evoked by excitatory synaptic transmission are increased by inhibition of extracellular carbonic anhydrase. Proc Natl Acad Sci USA 89:7786-7790.

Chen XH, Bezprozvanny I, Tsien RW (1996) Molecular basis of proton block of L-type $\mathrm{Ca}^{2+}$ channels. J Gen Physiol 108:363-374.

Chesler M (2003) Regulation and modulation of $\mathrm{pH}$ in the brain. Physiol Rev 83:1183-1221.

Congar P, Leinekugel X, Ben-Ari Y, Crepel V (1997) A long-lasting calciumactivated nonselective cationic current is generated by synaptic stimulation or exogenous activation of group I metabotropic glutamate receptors in CA1 pyramidal neurons. J Neurosci 17:5366-5379.

de Curtis M, Manfridi A, Biella G (1998) Activity-dependent pH shifts and periodic recurrence of spontaneous interictal spikes in a model of focal epileptogenesis. J Neurosci 18:7543-7551.

DeVries SH (2001) Exocytosed protons feedback to suppress the $\mathrm{Ca}^{2+}$ current in mammalian cone photoreceptors. Neuron 32:1107-1117.

Enoki R, Kiuchi T, Koizumi A, Sasaki G, Kudo Y, Miyakawa H (2004) NMDA receptor-mediated depolarizing after-potentials in the basal dendrites of CA1 pyramidal neurons. Neurosci Res 48:325-333.

Fan Y, Zou B, Ruan Y, Pang Z, Xu ZC (2005) In vivo demonstration of a late 
depolarizing postsynaptic potential in CA1 pyramidal neurons. J Neurophysiol 93:1326-1335.

Fedirko N, Svichar N, Chesler M (2006) Fabrication and use of high-speed concentric $\mathrm{H}^{+}$and $\mathrm{Ca}^{2+}$-selective microelectrodes suitable for in vitro extracellular recording. J Neurophysiol 96:919-924.

Fedirko N, Avshalumov M, Rice ME, Chesler M (2007) Regulation of postsynaptic $\mathrm{Ca}^{2+}$ influx in hippocampal CA1 pyramidal neurons via extracellular carbonic anhydrase. J Neurosci 27:1167-1175.

Fernandez de Sevilla D, Fuenzalida M, Porto Pazos AB, Buno W (2007) Selective shunting of the NMDA EPSP component by the slow afterhyperpolarization in rat CA1 pyramidal neurons. J Neurophysiol 97:3242-3255.

Fraser DD, MacVicar BA (1996) Cholinergic-dependent plateau potential in hippocampal CA1 pyramidal neurons. J Neurosci 16:4113-4128.

Gottfried JA, Chesler M (1994) Endogenous H+ modulation of NMDA receptor-mediated EPSCs revealed by carbonic anhydrase inhibition in rat hippocampus. J Physiol (Lond) 478:373-378.

Hanrahan JW, Tabcharani JA (1990) Inhibition of an outwardly rectifying anion channel by HEPES and related buffers. J Membr Biol 116:65-77.

Hestrin S, Nicoll RA, Perkel DJ, Sah P (1990) Analysis of excitatory synaptic action in pyramidal cells using whole-cell recording from rat hippocampal slices. J Physiol (Lond) 422:203-225.

Huang W, Smith SE, Chesler M (1995) Addition of carbonic anhydrase augments extracellular $\mathrm{pH}$ buffering in rat cerebral cortex. J Neurophysiol 74:1806-1809.

Huettner JE, Bean BP (1988) Block of N-methyl-D-aspartate-activated current by the anticonvulsant MK-801: selective binding to open channels. Proc Natl Acad Sci USA 85:1307-1311.

Iijima T, Ciani S, Hagiwara S (1986) Effects of the external pH on Ca channels: experimental studies and theoretical considerations using a two-site, two-ion model. Proc Natl Acad Sci USA 83:654-658.

Kaila K (1994) Ionic basis of GABAA receptor channel function in the nervous system. Prog Neurobiol 42:489-537.

Kelly T, Church J (2004) pH modulation of currents that contribute to the medium and slow afterhyperpolarizations in rat CA1 pyramidal neurones. J Physiol (Lond) 554:449-466.

Kuzmiski JB, MacVicar BA (2001) Cyclic nucleotide-gated channels contribute to the cholinergic plateau potential in hippocampal CA1 pyramidal neurons. J Neurosci 21:8707-8714.

Lavecchia R, Zugaro M (1991) Thermal denaturation of erythrocyte carbonic anhydrase. FEBS Lett 292:162-164.

MacGregor DG, Chesler M, Rice ME (2001) HEPES prevents edema in rat brain slices. Neurosci Lett 303:141-144.

Mameli M, Carta M, Partridge LD, Valenzuela CF (2005) Neurosteroidinduced plasticity of immature synapses via retrograde modulation of presynaptic NMDA receptors. J Neurosci 25:2285-2294.

Nowak L, Bregestovski P, Ascher P, Herbet A, Prochiantz A (1984) Magne- sium gates glutamate-activated channels in mouse central neurones. Nature 307:462-465.

Palmer MJ, Hull C, Vigh J, von Gersdorff H (2003) Synaptic cleft acidification and modulation of short-term depression by exocytosed protons in retinal bipolar cells. J Neurosci 23:11332-11341

Samson RD, Pare D (2005) Activity-dependent synaptic plasticity in the central nucleus of the amygdala. J Neurosci 25:1847-1855.

Schiller J, Schiller Y (2001) NMDA receptor-mediated dendritic spikes and coincident signal amplification. Curr Opin Neurobiol 11:343-348.

Schiller J, Major G, Koester HJ, Schiller Y (2000) NMDA spikes in basal dendrites of cortical pyramidal neurons. Nature 404:285-289.

Schiller Y (2004) Activation of a calcium-activated cation current during epileptiform discharges and its possible role in sustaining seizure-like events in neocortical slices. J Neurophysiol 92:862-872.

Schwiening CJ, Kennedy HJ, Thomas RC (1993) Calcium-hydrogen exchange by the plasma membrane Ca-ATPase of voltage-clamped snail neurons. Proc R Soc Lond B Biol Sci 253:285-289.

Somjen GG (1984) Acidification of interstitial fluid in hippocampal formation caused by seizures and by spreading depression. Brain Res 311:186-188.

Taira T, Smirnov S, Voipio J, Kaila K (1993) Intrinsic proton modulation of excitatory transmission in rat hippocampal slices. NeuroReport 4:93-96.

Taira T, Paalasmaa P, Voipio J, Kaila K (1995) Relative contributions of excitatory and inhibitory neuronal activity in alkaline transients evoked by stimulation of Schaffer collaterals in the rat hippocampal slice. J Neurophysiol 74:643-649.

Tang CM, Dichter M, Morad M (1990) Modulation of the N-methyl-Daspartate channel by extracellular $\mathrm{H}^{+}$. Proc Natl Acad Sci USA 87:6445-6449.

Tong C, Chen K, Chesler M (2006) Kinetics of activity-evoked pH transients and extracellular $\mathrm{pH}$ buffering in rat hippocampal slices. J Neurophysiol 95:3686-3697.

Tong CK, Chesler M (2000) Modulation of spreading depression by changes in extracellular pH. J Neurophysiol 84:2449-2457.

Traynelis SF, Cull-Candy SG (1990) Proton inhibition of N-methyl-Daspartate receptors in cerebellar neurons. Nature 345:347-350.

Vyklicky Jr L, Vlachova V, Krusek J (1990) The effect of external pH changes on responses to excitatory amino acids in mouse hippocampal neurones. J Physiol (Lond) 430:497-517.

Wu WW, Chan CS, Disterhoft JF (2004) Slow afterhyperpolarization governs the development of NMDA receptor-dependent afterdepolarization in CA1 pyramidal neurons during synaptic stimulation. J Neurophysiol 92:2346-2356.

Xiong ZQ, Stringer JL (2000) Extracellular pH responses in CA1 and the dentate gyrus during electrical stimulation, seizure discharges, and spreading depression. J Neurophysiol 83:3519-3524.

Yamamoto D, Suzuki N (1987) Blockage of chloride channels by HEPES buffer. Proc R Soc Lond B Biol Sci 230:93-100. 